no harmful effects could be attributed to the injection, even when given intravenously. The infections which responded to treatment were gastrointestinal ( $B$. coli), staphylococcal, streptococcal and pneumococcal types, while virus infections do not seem to respond.

This preparation from Penicillium notatum seemed exceptionally potent in the treatment of open wounds with pyrogenic mixed infections, and also when used intramuscularly for the treatment of pyrogenic and gastro-intestinal infections. The evidence of its value in old chronic infections is inconclusive. It appears that intramuscular injections are as efficient as intravenous injections. The preparation is standardized for the hyphæ content by the turbidity against barium sulphate (nephelometer) or by an indirect all-count in comparison with a drop of blood. The antibacterial activity can be assayed in vitro by the Florey-cup or by the Fleming dilution method, or in vivo by animal protection tests.

In human beings the preparation is well tolerated without toxic reactions or sensitization becoming apparent. The therapeutic response is prompt, usually within 3-4 hours after the first injection. Controlled clinical results have already been obtained in sulphonamide-resistant pneumonia, acute staphylococcal, streptococcal and other infections, and it is hoped they will be published shortly.

We wish to express our thanks to Mr. E. von Lustig-Lendva, who was responsible for carrying out the preliminary animal tests.

H. E. ENoch.

W. K. S. WALLERSTEINER.

50 South Audley Street, Grosvenor Square, London, W.1. Jan. 28.

\section{Origin of Indo-European Languages}

Commenting on Prof. Alexander Jobhannesson's recent article, Mr. Allan S. C. Ross' states: "In all languages known to us ... for the great majority of words, the connexion between sound and sense is random". But he does not say whether this also applies to the connexion between mouth gesture and sense, which was what Prof. Johannesson has been particularly investigating.

Yet it can scarcely be disputed that the sounds of speech are, in fact, a secondary effect of the gestures of articulation which produce the various sounds of speech. If this is so, then it would appear that the "excellent minute" of the Société de Linguistique which Mr. Ross quotes is out of date, and that the "origin of language" is now ripe for discussion, on the basis of mouth gesture.

Having made a fairly wide examination of the connexion between mouth gesture and sense in various languages, and of the meaning which hand gestures (in sign language) and mouth gestures (in speech) actually convey, I can offer evidence of the survival of significant mouth gestures. In English, for example, about 75 per cent of all the short words are 'gestural'; that is, the mouth gestures which produce the words are themselves a pantomimic representation of the primitive meaning of the words. Thus, of the 79 short words beginning with $G R$ (a gripping, surrounding, enclosing or clawing gesture), 73 per cent are gestural; of the 25 short words beginning with $S C R$-, $S K R$-, 88 per cent are gestural, and of the 39 short words beginning with $S T R$-, 90 per cent are gestural, while 100 per cent of short words ending in -OOP or -OUP are gestural.
In Chinese the same conditions obtain; and of 36 words pronounced $K U$ or its variants ( $K^{\prime} U, \chi U$, $\chi U A, K \ddot{U}$ and $K U A I) 34$ (94 per cent) are found to be gestural. Similarly, of 19 short Greek words beginning with $\gamma^{\lambda-}(G L), 15$ (78.9 per cent) are gestural. Such connexions can certainly not be described as random.

Mr. Ross also states that "linguistic changes which must have operated in the long period intervening" (that is, between the origination of a language and its development as a written language) "would certainly have quickly reduced a non-random soundsense relation to a random one". On this count also the gestural evidence is against him.

Investigation of the mouth gestures involved in "linguistic changes" and "ablaut" shows that, as a rule, the original significant gestures do not change ; what changes is the manner in which the individual gestures are made, the changes being mostly in the direction of unconsciously making the gesture easier to perform. Thus, a complete closure of the tongue against the throat, palate or back of the teeth may become a partial closure in the same position. A complete lip closure may become a partial closure, a voiced consonant may become unvoiced, or the level of the tongue or the opening of the lips may be varied, for convenience in combining a given vowel posture with a particular consonant gesture. In other words, the 'fashions' in performing the mouth gestures vary-like other human fashions-but the gestures persist. Philologists should study mouth gestures. If they fail to do so, they will be in no position to criticize Prof. Jóhannesson's theories.

Human speech is, admittedly, a highly important branch of human behaviour; if its votaries will study the system of gestures to which audible speech is due, philology will indeed become a science, andlinked with the study of sign language-will take its place as an essential part of anthropology.

R. A. S. Paget.

Cranmore Hall, Shepton Mallet.

${ }^{1}$ NATURE, 153, 257 (1944).

\section{Pectoral Gland in Apes and Monkeys}

Prof. Osman Hunc's interesting account of the gland on the chest of a male drill ${ }^{1}$ reminds me that nearly twenty years ago ${ }^{2}$ I described and figured a somewhat similarly situated gland in two adult male gibbons from Borneo. In these apes, the glandular area superficially is an elongated triangular patch of thickened skin sparsely covered with short hairs, and in one of the specimens with blackish secretion. It is broad above and narrowed below, and extends from the region of the inner ends of the collar-bones downwards and terminates in a point a little below the mammæ. Although I had one of these gibbons under observation in the Zoological Gardens at Regent's Park, London, neither I nor the keeper in charge ever saw the animal evince the least sign of being aware of the existence of the gland; but Prof. Hill's amusing description of the conduct of the drill in connexion with its pectoral gland shows that there is still a great deal of interesting information about the behaviour of wild animals to be learnt by observing them in captivity.

Zoological Department,

British Museum (Natural History), London, S.W.7.

${ }^{1}$ NATURE, 152, 199 (1944).

2 Proc. Zool. Soc., 1492 (1925). 